\title{
Correction to: A Review of Patisiran (ONPATTRO®) for the Treatment of Polyneuropathy in People with Hereditary Transthyretin Amyloidosis
}

\author{
Ivan Urits · Daniel Swanson · Michael C. Swett · Anjana Patel • \\ Kevin Berardino - Ariunzaya Amgalan · Amnon A. Berger • \\ Hisham Kassem (D) - Alan D. Kaye · Omar Viswanath
}

Published online: January 12, 2021

(C) The Author(s) 2021

\section{Correction to: Neurol Ther (2020) 9:301-315 https://doi.org/10.1007/s40120- 020-00208-1}

The middle initial of one of the authors, Alan Kaye, was missed in the original publication.

The complete name should read as Alan D. Kaye.

The original article has been corrected.

Open Access. This article is licensed under a Creative Commons Attribution-NonCommercial 4.0 International License, which permits any non-commercial use, sharing,

The original article can be found online at https://doi. org/10.1007/s40120-020-00208-1.

I. Urits $(\bowtie) \cdot$ A. A. Berger

Department of Anesthesiology, Critical Care, and Pain Medicine, Beth Israel Deaconess Medical Center-Harvard Medical School, Boston, MA, USA e-mail: iurits@bidmc.harvard.edu

D. Swanson - M. C. Swett · A. Patel - K. Berardino . A. Amgalan

Georgetown University School of Medicine,

Washington, DC, USA

H. Kassem

Department of Anesthesiology, Mount Sinai Medical Center, Miami Beach, FL, USA adaptation, distribution and reproduction in any medium or format, as long as you give appropriate credit to the original author(s) and the source, provide a link to the Creative Commons licence, and indicate if changes were made. The images or other third party material in this article are included in the article's Creative Commons licence, unless indicated otherwise in a credit line to the material. If material is not included in the article's Creative Commons licence and your intended use is not permitted by statutory regulation or exceeds the permitted use, you will need to obtain permission directly from the copyright holder. To view a copy of this licence, visit http:// creativecommons.org/licenses/by-nc/4.0/.

\footnotetext{
A. D. Kaye

Department of Anesthesiology, Louisiana State University Health Shreveport, Shreveport, LA, USA

O. Viswanath

Valley Anesthesiology and Pain

Consultants-Envision Physician Services, Phoenix, AZ, USA

O. Viswanath

Department of Anesthesiology, University of

Arizona College of Medicine-Phoenix, Phoenix, AZ, USA

O. Viswanath

Department of Anesthesiology, Creighton

University School of Medicine, Omaha, NE, USA
} 